\title{
Editorial
}

\section{Physiological instability of the spinal cord following injury}

The biomechanical instability of the vertebral column following injury is well documented. ${ }^{1-13}$ All of these authors have described various mechanisms of damage to the spinal axis with potential further displacement and mechanical damage to the spinal cord. These and many other authors have described various ways of dealing with the mechanical instability culminating in a wide range of conservative and surgical procedures all of which aim primarily at 'containment' of the biomechanical instability until natural healing of the spinal axis is achieved, hoping in the process that functional recovery of the undamaged spinal tracts is enhanced and most importantly ensuring the prevention of further cord damage and neurological loss.

What is not often appreciated is that delay in functional recovery of damaged spinal tracts and/or neurological deterioration can occur due to factors unrelated to mechanical compression of neural tissues.

It is a well known fact that patients with multiple sclerosis can exhibit symptoms and signs of neurological deterioration when they become pyrexial. Ischaemia of the spinal cord can also result in paralysis during aortic surgery or due to infarction of the anterior spinal artery. The vulnerability of the injured cord was recognised in the early 1950s. 'The spinal cord has more protective structures and circumstances than the brain but when these devices are overcome they exist probably to a lesser degree of resistance to injury'. ${ }^{14}$

The pathophysiological changes that occur in the injured cord with disruption of blood-brain barrier, impairment of autoregulation and cell membrane disturbance contributing to the cascade of pathogenic changes would understandably make the cord vulnerable not only to local mechanical damage but also to distant pathological processes.
Whilst all scientists do not seem satisfied that ischaemia alone is solely responsible for the electrophysiological and neuropathological changes, ${ }^{15-18}$ it is nevertheless agreed that ischaemia has a role in the development of the secondary injury in the spinal cord. Increased circulation time, ${ }^{19}$ alteration of vasomotor reactivity, ${ }^{20}$ accumulation of lactate, ${ }^{21}$ platelet aggregation related to endothelium changes, 22 and impairment of autoregulation ${ }^{23-25}$ are well documented in the laboratory.

The detrimental neurological effect of a combination of compression ischaemia in the dog has been documented by Gooding. ${ }^{26}$

In the clinical situation we have witnessed patients with biomechanically stable cervical and upper thoracic injuries developing postural hypotension, resulting in neurological deterioration, both prevented by the administration of ephedrine prior to mobilisation (El Masri, Frankel, Baker \& Pringle-personal communication). This prompted us to perform tilt table studies on all our patients with incomplete cord injuries, monitoring blood pressure and neurological status throughout the different degrees of tilting prior to mobilisation. Neurological deterioration associated with intraoperative hypotension during cervical decompression was reported by Bohlman. ${ }^{27}$

The profound effect of sepsis and hypoxia on the reflex activity of the injured cord is well documented by Guttmann. ${ }^{28}$

Unexplained progressive cord lesions without deformation of the canal were reported by Braakman \& Penning. ${ }^{29}$ The effects of various anaesthetic agents on the autoregulation of the injured spinal cord of experimental animals is unknown and might have an adverse effect on the cord.$^{30}$ It may be possible to explain both the occasional neurological deterioration that occurs despite the utmost surgical expert care, and the lack of convincing evidence of the neurological benefits of surgical decompression and 
stabilisation $^{31}$ by some interfering mechanism, possibly distant to the site of the injury and from which the injured and physiologically unstable cord is unable to protect itself.

The multisystem impairment that results from a spinal cord injury is a potential source of many pathological processes each of which can be detrimental to the patient in general and to the neurological status in particular. What is certain is that the cardiorespiratory and autonomic system status as well as the multiple sources of infection in these patients are at least as great a threat to the injured and physiologically unstable cord as is the biomechanical instability and neural tissue compression by the spinal axis.

The neurological outcome therefore depends not only on the quality and expertise of the management of the biomechanical instability of the spinal axis but also on the simultaneous provision of a quality and integrated expert management of the multisystem impairment, hence the importance of the management of patients with spinal injuries from an early stage in centres where a total patient care policy is well planned, well executed and carefully monitored.

W S El Masry FRCS Ed Assistant Editor, Paraplegia Consultant in Spinal Injuries Medical Director Midlands Centre for Spinal Injuries Robert Jones \& Agnes Hunt Orthopaedic Hospital Gobowen, Oswestry, Shropshire $S Y 107 A G, U K$

\section{References}

1 Watson Jones R (1931) Manipulative reduction of crush fractures of the spine. $\mathrm{Br}$ Med J 1: 300 .

2 Watson Jones R (1934) The treatment of fractures and fracture dislocations of the spine. J Bone Joint Surg 16: 30-45.

3 Nicholl EA (1949) Fractures of the dorsal lumbar spine. J Bone Joint Surg 31(B): 376-394.

4 Roaf R (1960) A study of the mechanisms of spinal injuries. J Bone Joint Surg 42(B): 810-823.

5 Roaf R (1972) International classification of spinal injuries. Paraplegia 10: 78-84.

6 Munroe D (1961) Treatment of fractures and dislocations of the cervical spine complicated by cervical cord and root injuries. $N$ Engl J Med 264: 573-582.

7 Holdsworth FW, Hardy A (1953) Early treatment of paraplegia from fractures of the thoracolumbar spine. J Bone Joint Surg 35(B): 540-550.

8 Holdsworth FW (1963) Fractures, dislocations and fracture dislocations of the spine. J Bone Joint Surg 45(B): 6-20.

9 Beatson TR (1963) Fractures and dislocations of the cervical spine. J Bone Joint Surg 45(B): 21-38.

10 Cheshire DJE (1969) The stability of the cervical spine following the conservative treatment of fractures and fracture dislocations. Paraplegia 7: 153-203.

11 Bedbrook GM (1971) Stability of spinal fractures and fracture dislocations. Paraplegia 9: 23-32.

12 White AA, Southwick WO, Panjabi MM Clinical instability in the lower cervical spine. A review of past and current concepts. Spine 1: 15-27.

13 Denis F (1983) The three column spine and its significance in the classification of acute thoracolumbar spinal injuries. Spine 8(8): 817.

14 Freeman LW, Wright TW (1953) Experimental observations of concussion and contusion of the spinal cord. Ann Surg 137: 433-443.

15 Tarlov IM (1972) Acute spinal cord compression paralysis. J Neurosurg 36: 10-20.

16 Bingham WG, Golman H, Friedman SJ, Murphy S, Yashou D, Hunt WE (1975) Blood flow in normal and injured monkey spinal cord. J Neurosurg 43: 162-171.

17 Korbine AI (1975) The neuronal theory of experimental traumatic spinal cord dysfunction Surg Neurol 3: 261-264.

18 Korbine IA, Evans ED, Rizzoli H (1978) Correlation of spinal cord blood flow and function in experimental compression. Surg Neurol 10: 54-59.

19 Wagner FC Jnr, Taslitz N, White RJ, Yashon D (1969) Vascular phenomena in the normal and traumatised spinal cord. Anat Rec 163: 281.

20 Ducker TB, Kindt GW (1971) The effect of trauma on the vasomotor control of spinal cord blood flow. Curr Top Surg Res 3: 163-171.

21 Locke GE, Yashon D, Feldman RA, Hunt WE (1971) Ischaemia in primate spinal cord injury. J Neurosurg 34: $614-617$.

22 Goodman JH, Bingham WG Jnr, Hunt WE (1979) Platelet aggregation in experimental spinal cord injury. Celbrastructural observations. Arch Neurology 36: 197-201. 
23 Griffiths IR (1976) Spinal cord blood flow after acute experimental cord injury in dogs. J Neurol Sci 27: 247-259.

24 Smith AJK, McCreery DB, Bloedel JR, Chou SN (1978) Hyperaemia CO2 responsiveness and autoregulation in the white matter following experimental spinal cord injury. J Neurosurg 48: 239-251.

25 Senter JH, Venes JL (1979) Loss of anteroregulation and post traumatic ischaemia following experimental spinal cord trauma. J Neurosurg 50: 198-206.

26 Gooding MR, Wilson CB, Hoff JT (1975) Effects of ischaemia and compression of the canine cervical spinal cord. J Neurosurg 43: 19-17.

27 Bohlman HH (1979) Acute fractures and dislocations of the cervical spine. An analysis of three hundred hospitalised patients and review of the literature. J Bone Joint Surg 61(A): 1119-1142.

28 Guttman L (1973) Spinal Cord Injuries. Comprehensive Management and Research. Blackwell Scientific Publications, Oxford: 234.

29 Braakman R, Penning L (1976) Injuries of the cervical spine. In PJ Vinken, GW Bruyn. Handbook of Clinical Neurology. Vol 25. North Holland Publishing Co. Amsterdam and Oxford: 277.

30 Hickey R, Albin MS, Bunegin L, Gelineau J (1986) Autoregulation of spinal cord blood flow: Is the cord blood flow a microcosm of the brain? Stroke 17: 1183-1189.

31 Tator CH, Duncan EG, Edmonds VE, Lapizak LI, Andrews DF (1987) Comparison of surgical and conservative management in 208 patients with acute spinal cord injury. Can J Neurol Sci 14: 60-69. 